\title{
LONG-TERM RESULTS OF GEOMEDIC TOTAL KNEE REPLACEMENT
}

\author{
D. RILEY, J. E. WOODYARD
}

\author{
From Stafford District General Hospital
}

\begin{abstract}
Seventy-one Geomedic total knee replacements were reviewed retrospectively at a maximum of eight and a half years. The prosthesis was found to be successful in its primary aim of relieving pain.

However, there was an overall failure rate of $18.3 \%$. Analysis of the results by an actuarial method allowed comparison with other prostheses. The factors involved in failure are discussed.
\end{abstract}

The Geomedic total knee arthroplasty has been in general use since 1972, and a number of workers have published the results of follow-up to a maximum of six and a quarter years (Skolnick. Coventry and Ilstrup 1976; Riley and Hungerford 1978; Wilson, Fajgenbaum and Venters 1980; Hunter et al. 1982). A failure rate of between $4 \%$ and $12 \%$ has been reported in these series, the majority of failures being due to loosening of the tibial component.

The purpose of this present study was to ascertain the success of this prosthesis over a maximum follow-up of eight and a half years, and, using the survivorship method, to compare this success rate with that of other prostheses which have been implanted for a similar length of time.

\section{PATIENTS AND METHODS}

Since 197580 Geomedic knee replacements have been carried out by two surgeons in 54 patients in the Stafford district. The pre-operative data in five patients (eight knees) was insufficient, and one patient died immediately after operation, leaving 71 knees available for follow-up. Of the 48 patients 11 were men and 37 women. The average age at operation was 61 years (range 25 to 79 ). Forty-eight operations were for rheumatoid arthritis and 23 for osteoarthritis.

The main indications for operation were pain which could not be relieved by conservative methods, and a radiographic appearance suggesting that the less radical procedures of synovectomy or osteotomy would be inadequate.

The operation was carried out using the technique described by Coventry et al. in 1972. Antibiotic cover

D. Riley, FRCS. Orthopaedic Registrar

Mayday Hospital, Mayday Road. Thornton Heath, Surrey CR4 7YE England.

J. E. Woodyard, FRCS, Consultant Orthopaedic Surgeon

Stafford District General Hospital, Weston Road. Stafford ST16 3SA. England.

Requests for reprints should be sent to Mr D. Riley.

( 1985 British Editorial Society of Bone and Joint Surgery $0301620 \times 85 / 4135 \$ 2.00$ was provided by the use of flucloxacillin, $500 \mathrm{mg}$ three times daily for five days, starting on the morning of operation. Erythromycin was substituted in those patients sensitive to the penicillins. A Robert Jones bandage was used for the first five to seven days after operation and flexion exercises were then begun if the wound was satisfactory. If flexion was still limited and not improving spontaneously at two weeks, a manipulation was carried out under anaesthesia.

Table I. Grades used for assessment of knee function

\begin{tabular}{llll}
\hline Grade & Pain & Walking time & $\begin{array}{l}\text { Range of } \\
\text { movement } \\
\text { (degrees) }\end{array}$ \\
\hline 1 & Nil or minimal & $->60 \mathrm{mins}$ & $>100$ \\
2 & Slight & $10-60 \mathrm{mins}$ & $81-100$ \\
3 & $\begin{array}{l}\text { Moderate interference with } \\
\text { sleep or activity }\end{array}$ & $010 \mathrm{mins}$ & $45-80$ \\
4 & Severe & Not outdoors & $<45$ \\
\hline
\end{tabular}

All the patients were reviewed at a special follow-up clinic between 2 and 100 months after operation. The knees were assessed on a scale from Grade 1 to Grade 4 for each of three factors: pain, walking time and range of movement (Table I). In addition, the presence of deformity-defined as varus, or more than $10^{\circ}$ of either valgus or fixed flexion deformity-was noted. This method of assessment represents a simplified version of that recommended by the British Orthopaedic Association Research Sub-Committee (Aichroth et al. 1978).

The results were then compared with the preoperative assessment, and a survival curve for the prostheses was constructed according to the method suggested by Tew and Waugh (1982).

\section{RESULTS}

Complications. One patient suffered a fatal pulmonary embolus. No other deaths were attributable to surgery. In addition, there were two clinically significant deep venous thromboses, three patients had wound haematomas and one had a superficial wound infection. 
Further surgery (including manipulation, skin grafting and drainage of haematoma) was required in five patients in addition to those subsequently needing revision or arthrodesis, which are discussed later as failures.

Pain. The overall improvement in pain in those knees assessed at more than one year after operation was $72 \%$ of the maximum possible (Fig. 1).

Walking time. The overall improvement in walking time was $33 \%$ (Fig. 2), but there was a significant difference $(P<0.01)$ between those patients with rheumatoid arthritis and those with osteoarthritis; the former, being restricted by involvement of other joints, had only a $30 \%$ improvement compared with $52 \%$ in the latter.

Range of movement. The overall improvement was only $14 \%$, but only three patients had less than $45^{\circ}$ arc of flexion (Fig. 3).

Deformity. Before operation 53 knees were deformed. At follow-up 10 were deformed, all in patients who had had pre-operative deformity.
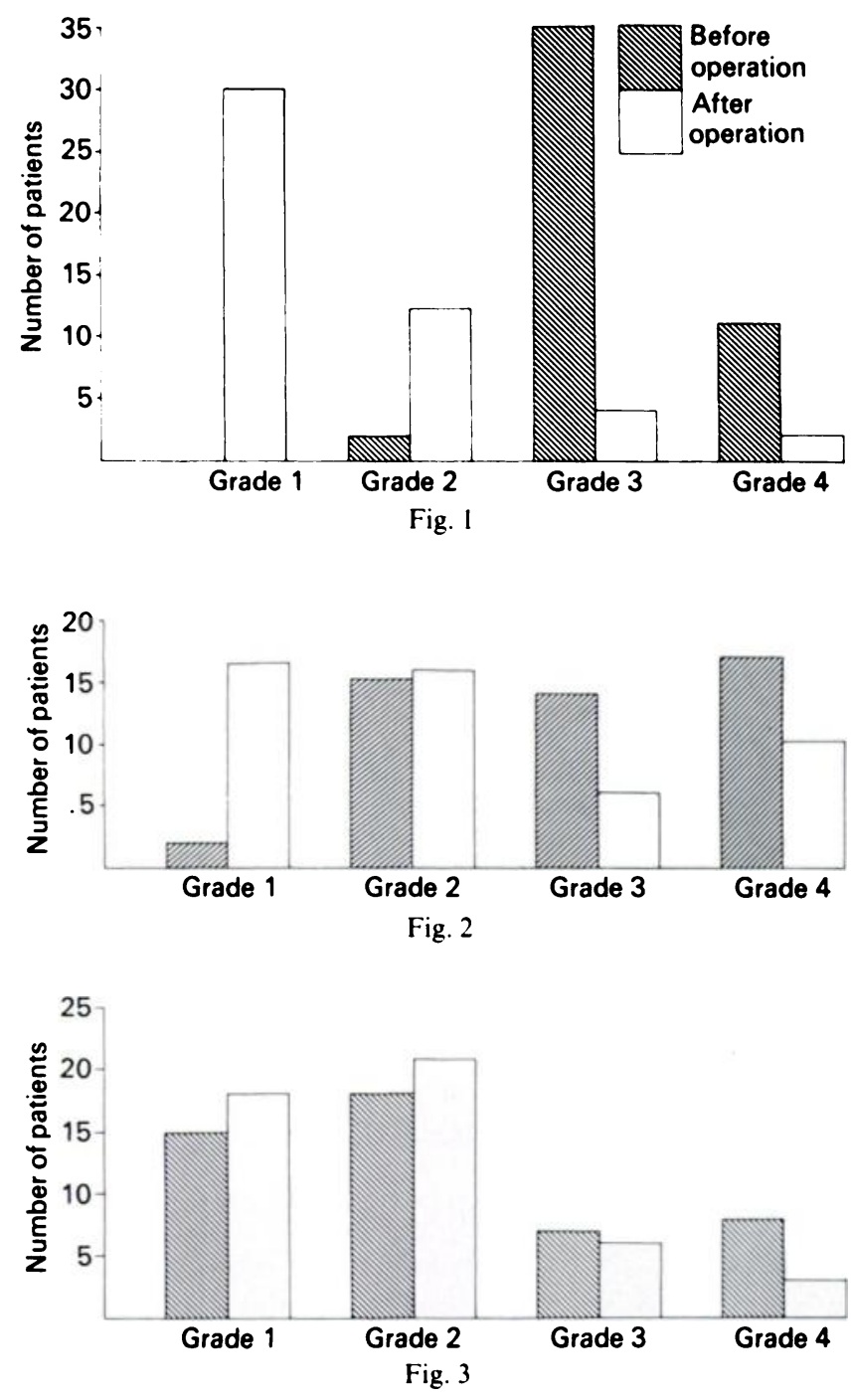

Distribution of grades before and after operation. Figure 1-Pain. Figure 2-Walking time. Figure 3-Range of movement.

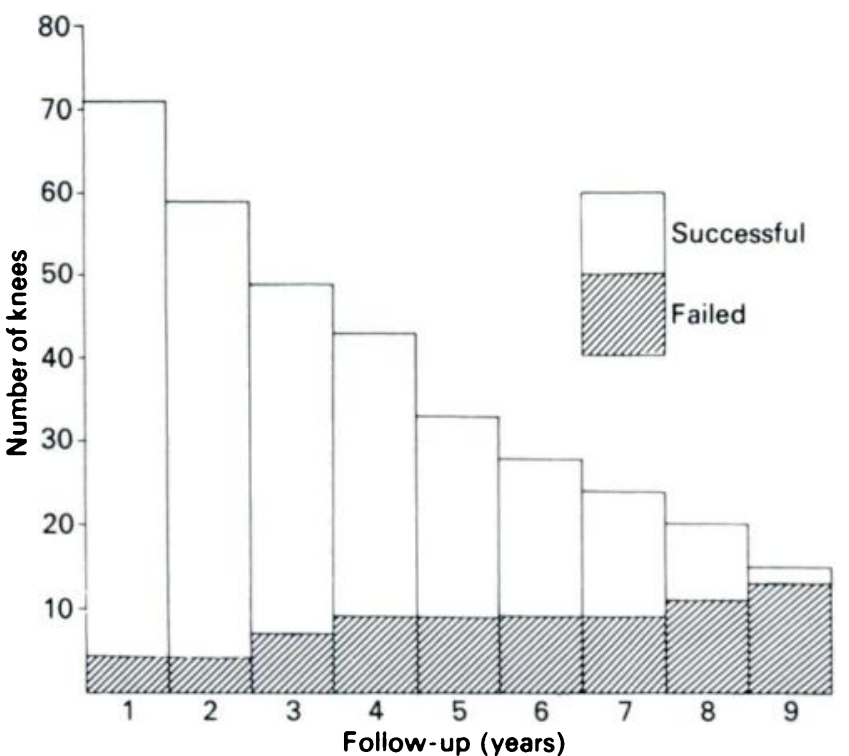

Fig. 4

Comparison between cumulative failure curve and cumulative survival curve. Failures refer to prostheses, not patients; some patients whose first prosthesis failed. later had satisfactory replacements.

Failures. Failure was defined as the development of severe pain which could be attributed to the prosthesis, or the need to remove the prosthesis for infection or mechanical loosening. The overall failure rate was $18.3 \%$. The cumulative failure curve is illustrated in Figure 4 and it can be seen that, in this series, there appear to be two "failure populations": those who failed early (up to four years), and those who failed late (after seven years). The early failures tended to be associated with technical difficulties or infection, while the later ones did not, suggesting that unavoidable biomechanical factors contributed more to these late failures (Table II).

Table II. Analysis of failed prostheses

\begin{tabular}{cll}
$\begin{array}{l}\text { Time of failure } \\
\text { (months) }\end{array}$ & Type of failure & Predisposing factors \\
\hline 6 & M & Too much femoral bone excised \\
6 & I & \\
9 & I & \\
12 & M & Malposition of femoral component \\
26 & M & Valgus not corrected \\
28 & M & Difficult operation \\
30 & M & Previous revision \\
38 & M & \\
42 & M & \\
85 & M & \\
91 & M & \\
97 & M & \\
100 & M & \\
\hline
\end{tabular}

M. mechanical: I. infection 
Table III. Comparison of annual cumulative success rates of three published series

\begin{tabular}{llll} 
Years & $\begin{array}{l}\text { Tew and Waugh } \\
1982\end{array}$ & $\begin{array}{l}\text { Grimer et al. } \\
1984\end{array}$ & $\begin{array}{l}\text { Present } \\
\text { series }\end{array}$ \\
01 & 98 & 100 & 94 \\
12 & 94 & 100 & 94 \\
23 & 83 & 95.3 & 87 \\
34 & 74 & 88.5 & 81 \\
45 & 63 & 77 & 81 \\
56 & 46 & 66.2 & 81 \\
67 & 33 & 58.4 & 81 \\
78 & 24 & 41.7 & 62 \\
89 & 18 & 13.9 & 21 \\
\hline
\end{tabular}

The distribution of age, sex and pathology (rheumatoid arthritis or osteoarthritis) was the same for the failed patients as for the group as a whole.

The figures have been analysed by the survivorship method advocated by Tew and Waugh (1982) to give an annual cumulative success rate. The figures from this series are compared with those from the composite series of Tew and Waugh (1982) which assessed Freeman, Sheehan and Manchester prostheses, and that of Grimer, Karpinski and Edwards (1984), which assessed the Stanmore knee replacement (Table III). A similar pattern of survival was found in all three series.

\section{DISCUSSION}

The Geomedic knee replacement has the advantage of requiring relatively little bone removal, which makes salvage surgery easier should the prosthesis fail, and its action as a spacer confers stability on a knee in which there is some degree of ligamentous laxity. This prosthesis is therefore appropriate for use in a large number of patients requiring total knee arthroplasty.
Our study has shown that the prime objective of pain relief is achieved satisfactorily and without detriment to the function of the knee. The failure rate compares favourably with that of other prostheses followed for a similar length of time. Various other designs of knee replacement are now available which claim to have overcome some of the problems of fixation, particularly of the tibial component. However, few of these have had a sufficiently long follow-up to allow valid comparison with the older designs such as the Geomedic model.

We conclude therefore that total knee replacement with the Geomedic prosthesis is a satisfactory procedure for the relief of arthritic pain, but that the long-term prognosis for survival of the prosthesis (beyond six or seven years) must remain guarded. In this respect it appears to differ little from the other prostheses which have been available for a similar length of time. It is to be hoped that the newer designs fulfil the expectation of a longer period before failure.

We wish to thank Mr J. E. D. Bramley for allowing us to include his patients in the study.

\section{REFERENCES}

Aichroth P, Freeman MAR, Smillie IS, Souter WA. A knee function assessment chart. J Bone Joint Surg [Br] 1978:60 B:308 9.

Coventry MB, Finerman GAM, Riley LH, Turner RH, Upshaw JE. A new geometric knce for total knee arthroplasty. Clin Orthop 1972: 83: 15762 .

Grimer RJ, Karpinski MRK, Edwards AN. The long-term results of Stanmore total knee replacements. J Bone Joinı Surg $[B r]$ 1984: 66 B: 5562

Hunter JA, Zoma AA, Scullion JE, et al. The geometric knee replacement in polyarthritis. J Bone Joint Surg $[B r]$ 1982:64 B:95 8.

Riley LH Jr, Hungerford DS. Geometric total knee replacement for treatment of the rheumatoid knee. J Bone Joint Surg $[\mathrm{Am}]$ 1978: 60 A: 5237 .

Skolnick MD, Coventry MB, Ilstrup DM. Geometric total knee arthroplasty: a two-year follow-up study. J Bone Joint Surg $[\mathrm{Am}]$ 1976;58 A:749 53

Tew M, Waugh W. Estimating the survival time of knee replacements. $J$ Bone Joint Surg [Br] 1982:64 B:579 82.

Wilson FC, Fajgenbaum DM, Venters GC. Results of knee replacement with the Walldius and geometric prostheses: a comparative study. $J$ Bone Joint Surg $[\mathrm{Am}]$ 1980:62 A:497 503 